Article

\title{
Electrodeposition of Manganese-Nickel Oxide Films on a Graphite Sheet for Electrochemical Capacitor Applications
}

\author{
Hae-Min Lee ${ }^{1}$, Kangtaek Lee ${ }^{2}$ and Chang-Koo Kim ${ }^{1}$ * \\ 1 Department of Chemical Engineering and Division of Energy Systems Research, Ajou University, \\ Suwon 443-749, Korea; E-Mail: yihaemin@gmail.com \\ 2 Department of Chemical and Biomolecular Engineering, Yonsei University, Seoul 120-749, Korea; \\ E-Mail:ktlee@yonsei.ac.kr
}

* Author to whom correspondence should be addressed; E-Mail: changkoo@ ajou.ac.kr; Tel.: +82-31-219-2389; Fax: +82-31-219-1612.

Received: 15 November 2013; in revised form: 26 December 2013 / Accepted: 30 December 2013 / Published: 9 January 2014

\begin{abstract}
Manganese-nickel (Mn-Ni) oxide films were electrodeposited on a graphite sheet in a bath consisting of manganese acetate and nickel chloride, and the structural, morphological, and electrochemical properties of these films were investigated. The electrodeposited Mn-Ni oxide films had porous structures covered with nanofibers. The $\mathrm{X}$-ray diffractometer pattern revealed the presence of separate manganese oxide $\left(\gamma-\mathrm{MnO}_{2}\right)$ and nickel oxide (NiO) in the films. The electrodeposited Mn-Ni oxide electrode exhibited a specific capacitance of $424 \mathrm{~F} / \mathrm{g}$ in $\mathrm{Na}_{2} \mathrm{SO}_{4}$ electrolyte. This electrode maintained $86 \%$ of its initial specific capacitance over 2000 cycles of the charge-discharge operation, showing good cycling stability.
\end{abstract}

Keywords: Mn-Ni oxide films; electrodeposition; supercapacitor; specific capacitance; cycling stability

\section{Introduction}

Electrochemical capacitors are attracting significant interest owing to their potential role in power storage of electric and fuel cell vehicles. Electrochemical capacitors can be classified into two types according to their charge storage mechanisms [1,2]: electric double layer capacitor (EDLC) and redox supercapacitor (or pseudo-capacitor). EDLCs mainly utilize the nonfaradaic charge separation at the 
electrode/electrolyte interface. Redox supercapacitors make use of a reversible redox reaction in order to store charges. The behavior of redox supercapacitors is typically termed "pseudo-capacitance" and resembles a rechargeable battery more than a traditional capacitor. In the case of redox supercapacitors, various noble and transition metal oxides (e.g., $\mathrm{RuO}_{2}, \mathrm{CoO}_{x}, \mathrm{NiO}_{x}, \mathrm{MnO}_{2}$, etc.) and conducting polymers have been employed as electrode materials [3-7]. Among these materials, ruthenium oxide has been found to be a successful redox supercapacitor exhibiting a specific capacitance up to $720 \mathrm{~F} / \mathrm{g}$ [3]. However, cost is a prohibitive factor in the large-scale commercial production of ruthenium oxide as a redox supercapacitor.

Manganese and its oxides have received much attention as an alternative to the ruthenium oxide in electrochemical capacitor applications because of their satisfactory electrochemical performance, relatively low cost, natural abundance, and so on $[5,8,9]$. Several methods, including hydrothermal synthesis [10], chemical bath deposition [11], sol-gel method [12], and co-precipitation [13], have been used to produce manganese oxide electrodes for electrochemical capacitors. However, these methods produce oxide powders and the use of oxide powders is complicated and inconvenient in making electrodes. It needs several sequential treatments such as synthesizing powders, mixing them with a conducting agent and a binder, and then making electrodes [14]. A more effective method to prepare manganese oxide electrodes for electrochemical capacitor applications is electrodeposition because it leads to a direct deposition of oxide films on an electrode. In addition, electrochemical manganese dioxides which are in the forms of $\alpha-, \beta-$, and $\gamma-\mathrm{MnO}_{2}$ exhibit better electrochemical properties for electrochemical capacitor applications than natural manganese dioxide and chemically prepared manganese dioxide [15]. There are also several reports that binary metal oxides such as manganese-nickel oxide and manganese-cobalt oxide enhance the electrochemical capacitive performance of manganese oxides and have better electrochemical properties than single metal oxide [16-20].

In the present work, we have developed a bath consisting of manganese acetate and nickel chloride for the electrodepositon of manganese-nickel (Mn-Ni) oxide films as electrochemical capacitor electrodes. The structural, morphological, and electrochemical properties of the electrodeposited manganese-nickel oxide films were discussed.

\section{Results and Discussion}

\subsection{Formation Mechanism of the Electrodeposited Mn-Ni Oxide Films}

The anodic electrodeposition of manganese oxide in an electrolyte containing $\mathrm{Mn}^{2+}$ ions can be described by the following Equation [9]:

$$
\mathrm{Mn}^{2+}+2 \mathrm{H}_{2} \mathrm{O} \rightarrow \mathrm{MnO}_{2}+4 \mathrm{H}^{+}+2 \mathrm{e}^{-}
$$

In Equation (1), the oxidation state of $\mathrm{Mn}$ increases from +2 to +4 . Since it is improbable that two electrons are transferred in a single step, the formation of $\mathrm{MnO}_{2}$ from $\mathrm{Mn}^{2+}$ occurs concomitantly with the oxidation of water molecules. The detailed intermediate steps for the overall reaction of Equation (2) are as follows:

$$
\begin{aligned}
& 2 \mathrm{Mn}^{2+} \rightarrow 2 \mathrm{Mn}^{3+}+2 \mathrm{e}^{-} \\
& 2 \mathrm{Mn}^{3+} \rightarrow \mathrm{Mn}^{2+}+\mathrm{Mn}^{4+}
\end{aligned}
$$




$$
\begin{gathered}
\mathrm{Mn}^{4+}+4 \mathrm{H}_{2} \mathrm{O} \rightarrow \mathrm{Mn}(\mathrm{OH})_{4}+4 \mathrm{H}^{+} \\
\mathrm{Mn}(\mathrm{OH})_{4} \rightarrow \mathrm{MnO}_{2}+2 \mathrm{H}_{2} \mathrm{O}
\end{gathered}
$$

The deposition of nickel oxide makes a use of nickel hydroxide precipitation. Nickel hydroxide is formed on the electrode such that:

$$
\mathrm{Ni}^{2+}+2 \mathrm{OH}^{-} \rightarrow \mathrm{Ni}(\mathrm{OH})_{2}
$$

Nickel hydroxide is subsequently involved in the electrochemical reactions of Equations (8) and (9) $[21,22]$ :

$$
\begin{gathered}
\mathrm{Ni}(\mathrm{OH})_{2}+\mathrm{OH}^{-} \rightarrow \mathrm{NiO}-\mathrm{OH}+\mathrm{H}_{2} \mathrm{O}+\mathrm{e}^{-} \\
\mathrm{NiO}-\mathrm{OH}+\mathrm{OH}^{-} \rightarrow \mathrm{NiO}_{2}+\mathrm{H}_{2} \mathrm{O}+\mathrm{e}^{-}
\end{gathered}
$$

Finally, the eletrodeposition of nickel oxide in an electrolyte containing $\mathrm{Ni}^{2+}$ ions can be represented by the Equation (10):

$$
\mathrm{Ni}(\mathrm{OH})_{2}+2 \mathrm{OH}^{-} \rightarrow \mathrm{NiO}_{2}+2 \mathrm{H}_{2} \mathrm{O}+2 \mathrm{e}^{-}
$$

\subsection{Structural, Morphological, and Electrochemical Properties of the Electrodeposited Mn-Ni}

\section{Oxide Films}

The SEM (Hitachi, Tokyo, Japan) image of the electrodeposited Mn-Ni oxide film is shown in Figure 1. The substrate was well covered with nanofibers. Porous spaces were observed between the nanofibers, enhancing the redox process. This type of morphology is favorable for electrochemical capacitor applications owing to its large surface area.

Figure 1. SEM image of the electrodeposited Mn-Ni oxide film.

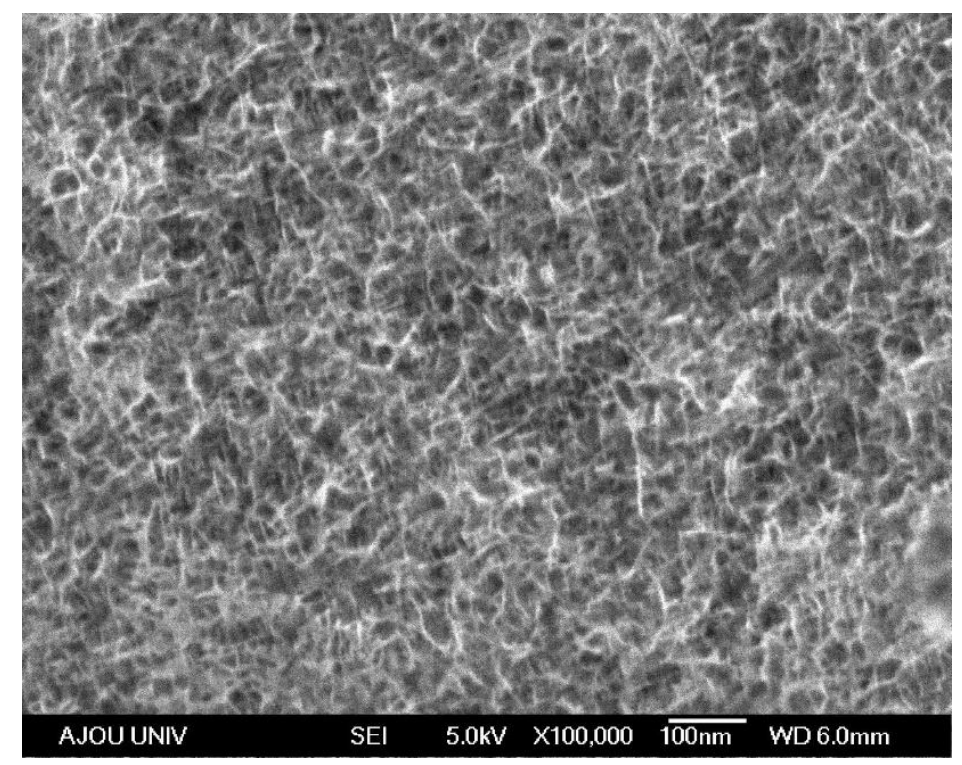

Figure 2 represents the pore size distribution of the electrodeposited Mn-Ni oxide film. The size of the pores in the film was mainly distributed in the range of $2-20 \mathrm{~nm}$. 
Figure 2. Pore size distribution of the electrodeposited Mn-Ni oxide film.

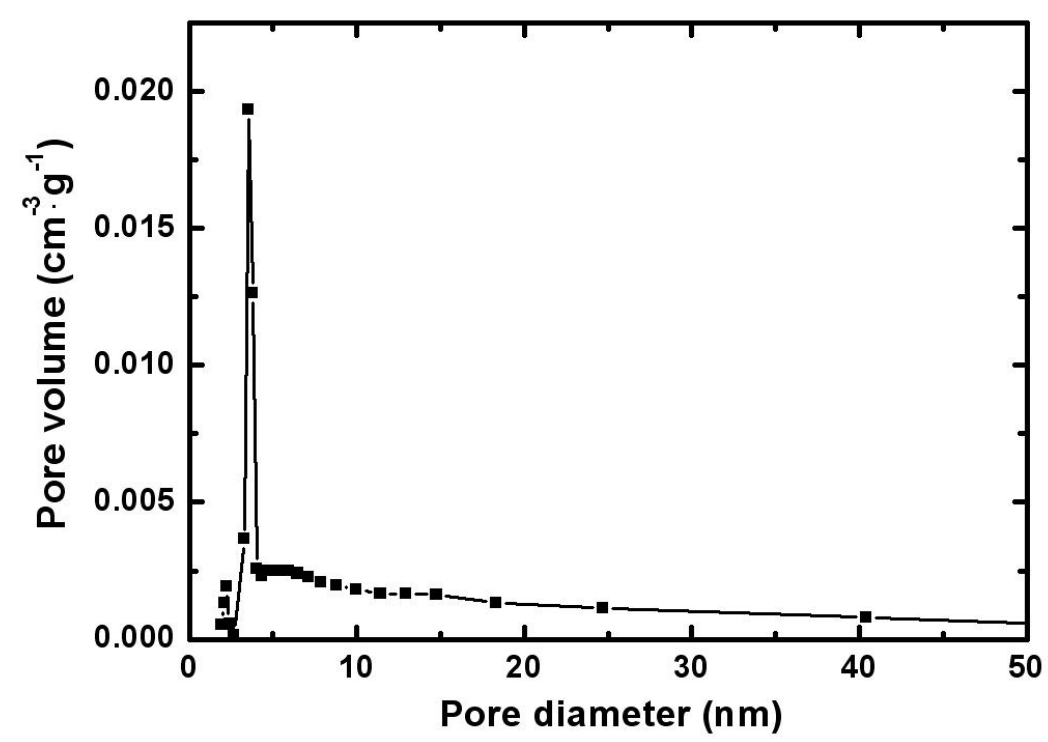

Figure 3 shows the XRD (Rigaku, Tokyo, Japan) patterns of the Mn-Ni oxides electrodeposited on a graphite sheet. The peaks at $26.4^{\circ}, 44.4^{\circ}, 54.5^{\circ}, 59.7^{\circ}, 77.2^{\circ}$, and $83.2^{\circ}$ represented carbon in the substrate (graphite sheet) [JCPDS No. 41-1487]. The peaks at $22.1^{\circ}$ and $34.4^{\circ}$ indicated that manganese oxide existed in the form of $\gamma-\mathrm{MnO}_{2}$ [JCPDS No. 14-0644]. Nickel oxides were found to be in the form of $\mathrm{NiO}$, resulting from the peaks at $37.2^{\circ}, 43.2^{\circ}$, and $62.8^{\circ}$. The XRD spectrum suggested that separate manganese oxide $\left(\gamma-\mathrm{MnO}_{2}\right)$ and nickel oxide $(\mathrm{NiO})$, not in the form of composites, were obtained using electrodeposition.

Figure 3. XRD spectrum of the electrodeposited Mn-Ni oxide film.

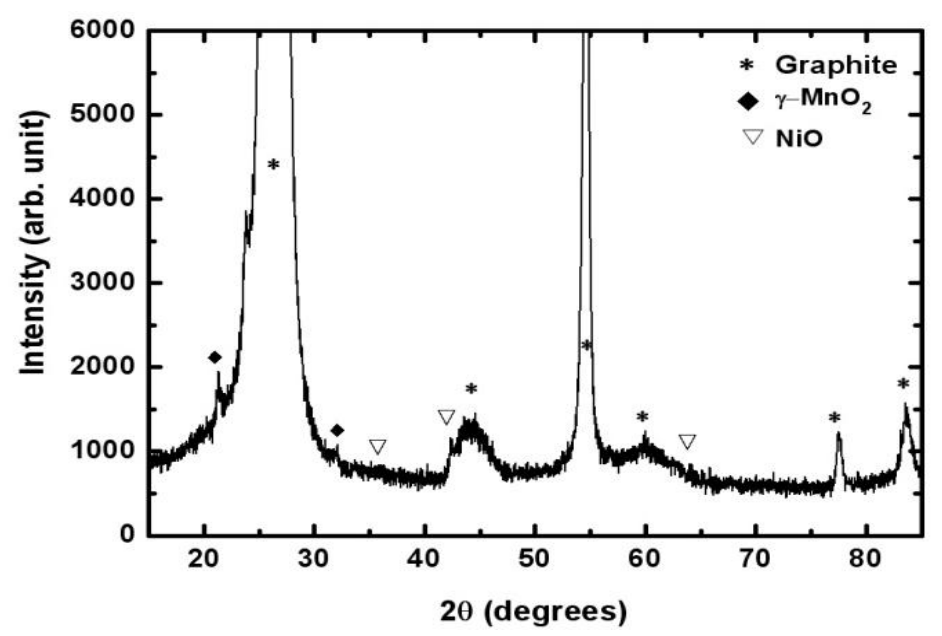

The surface composition of the electrodeposited Mn-Ni oxide film was analyzed by XPS (Thermo Fisher Scientific, East Grinstead, UK). Figure 4 shows the XPS spectrum of the Mn-Ni oxide film electrodeposited from an electrolyte containing $0.1 \mathrm{M}$ of manganese acetate and $0.2 \mathrm{M}$ of nickel chloride. The survey scan (Figure 4a) shows that the film contained $\mathrm{Mn}, \mathrm{Ni}$, and $\mathrm{O}$. The peak representing $\mathrm{C}$ due to the substrate (graphite sheet) was also observed. A higher resolution of the $\mathrm{Mn}$ $2 \mathrm{P}_{3 / 2}$ and $\mathrm{Ni} 2 \mathrm{P}_{3 / 2}$ spectra revealed that the peak at $642.6 \mathrm{eV}$ corresponded to manganese (IV) 
oxide [23] while the peak at $855.2 \mathrm{eV}$ represented the presence of nickel (II) oxide [24] in the film. A quantitative analysis using XPS yielded a surface composition of $\mathrm{Mn}_{0.24} \mathrm{Ni}_{0.05} \mathrm{O}_{0.71}$.

Figure 4. XPS spectra of the electrodeposited Mn-Ni oxide films. (a) survey scan; (b) $\mathrm{Mn} 2 \mathrm{P}_{3 / 2}$ electron; and (c) $\mathrm{Ni} 2 \mathrm{P}_{3 / 2}$ electron.

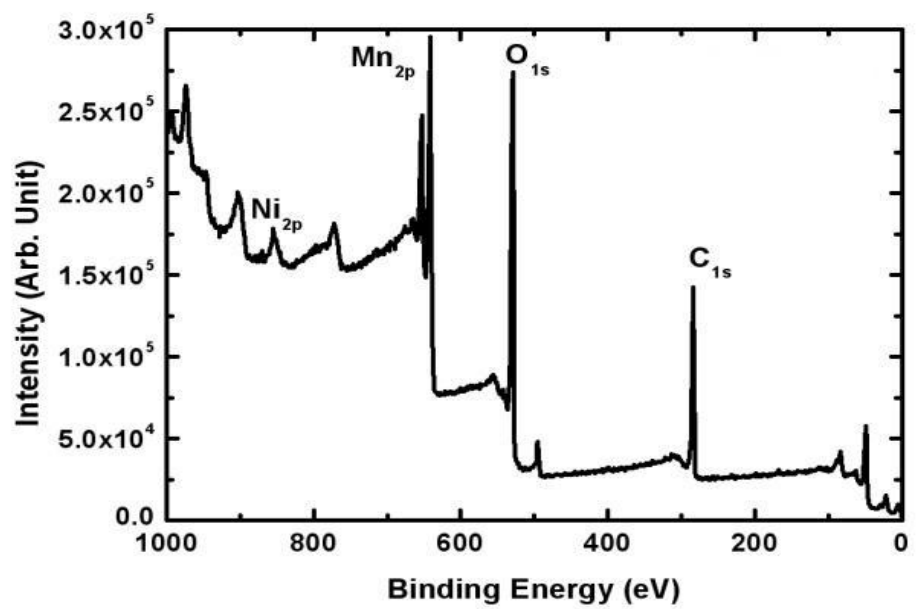

(a)

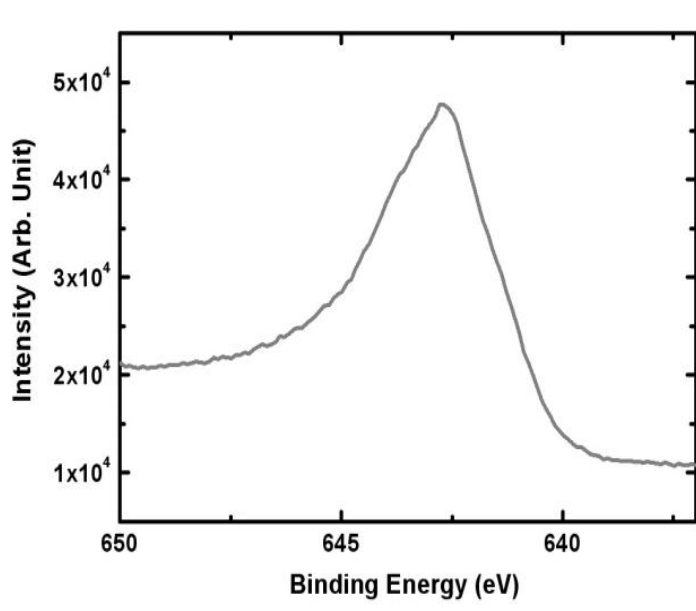

(b)

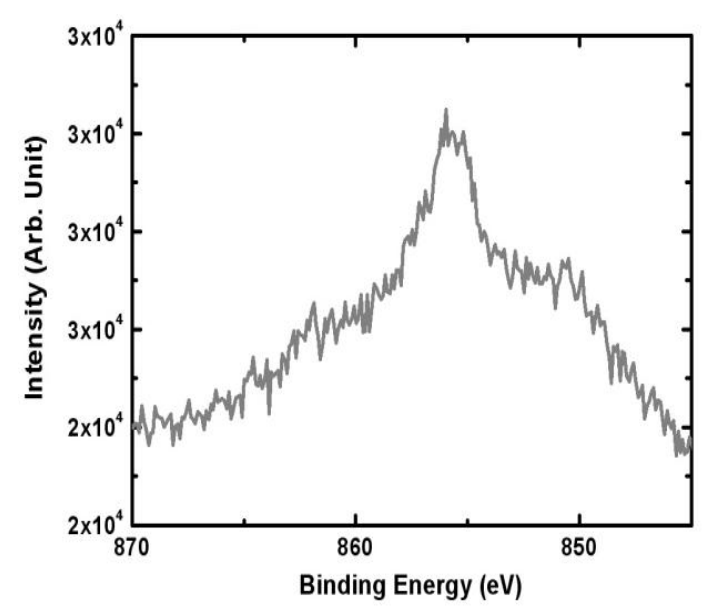

(c)

Figure 5 shows the cyclic voltammograms of the Mn-Ni oxide electrode electrodeposited at various scan rates. $\mathrm{CVs}$ were measured from -0.2 to $+1.0 \mathrm{~V} v s$. $\mathrm{Ag} / \mathrm{AgCl}$ in the $0.5 \mathrm{M} \mathrm{Na}_{2} \mathrm{SO}_{4}$ electrolyte. The $\mathrm{CV}$ curve was shaped as an asymmetrically closed box at all scan rates. This indicates that the capacitance characteristics of the electrodeposited Mn-Ni oxide electrode are distinguished from the electric double-layer capacitance whose CV curve is nearly an ideal rectangular shape. Figure 5 also shows that the area under the curve increased with the scan rate. This implies that the voltammetric current was proportional to the scan rate, corresponding to a capacitive behavior. Based on the $\mathrm{CV}$ measurements, the capacitance of the electrodeposited $\mathrm{Mn}-\mathrm{Ni}$ oxide electrode was calculated from Equation (10) in "Experimental Section". The specific capacitance of the electrodeposited Mn-Ni oxide electrode was found to be $424 \mathrm{~F} / \mathrm{g}$ at a scan rate of $20 \mathrm{mV} / \mathrm{s}$ in $0.5 \mathrm{M} \mathrm{Na}_{2} \mathrm{SO}_{4}$ electrolyte. 
Figure 5. Cyclic voltammograms of the electrodeposited $\mathrm{Mn}-\mathrm{Ni}$ oxide electrode in $0.5 \mathrm{M}$ $\mathrm{Na}_{2} \mathrm{SO}_{4}$ at scan rates of (a) 20; (b) 60; and (c) $100 \mathrm{mV} / \mathrm{s}$.

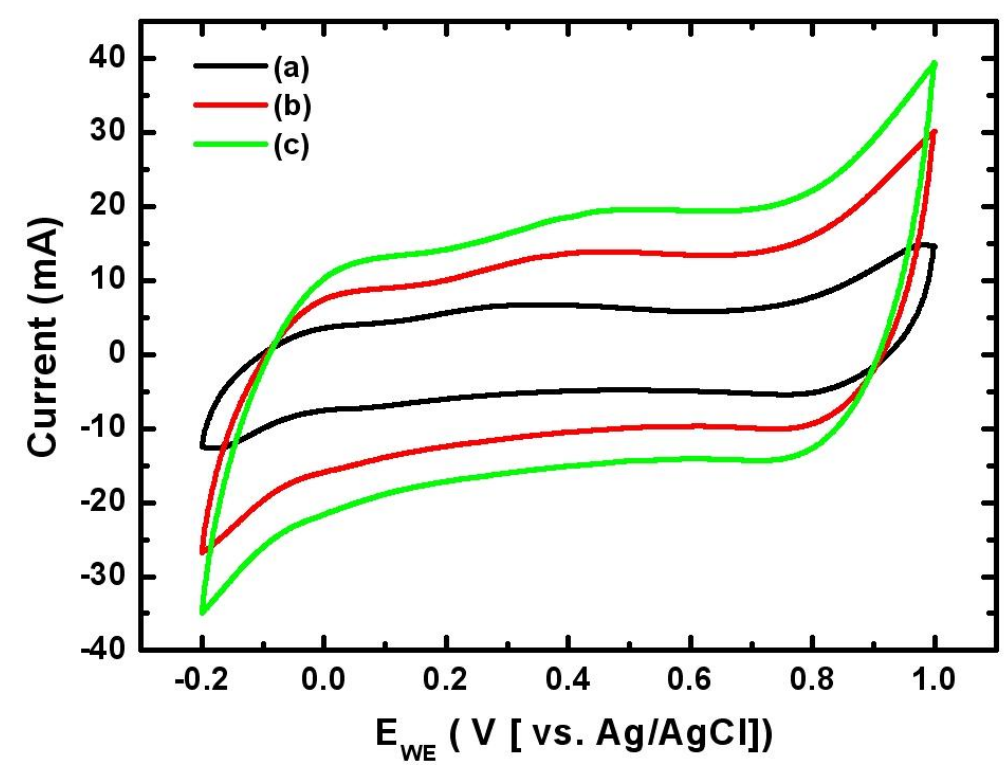

Figure 6 shows the first charge-discharge cycle of the electrodeposited Mn-Ni oxide electrode. The charge-discharge curve was nearly symmetric in the range between 0 and $0.85 \mathrm{~V}$ ( $v s . \mathrm{Ag} / \mathrm{AgCl}$ ), indicating that a good capacitive behavior of the electrodeposited $\mathrm{Mn}-\mathrm{Ni}$ oxide electrode was observed.

Figure 6. Charge-discharge curve of the electrodeposited $\mathrm{Mn}-\mathrm{Ni}$ oxide electrode in $0.5 \mathrm{M} \mathrm{Na}_{2} \mathrm{SO}_{4}$.

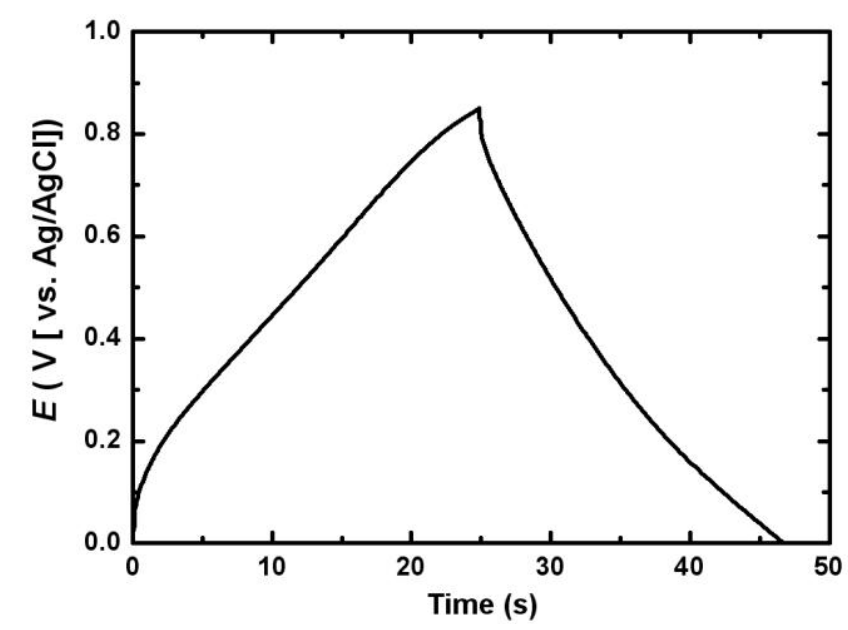

To evaluate the stability of the Mn-Ni oxide electrode, the charge-discharge cycling test at a current of $5 \mathrm{~mA}$ test was performed. Figure 7 shows the capacitance of the $\mathrm{Mn}-\mathrm{Ni}$ oxide electrode over 2000 cycles. The specific capacitance decreased to about $380 \mathrm{~F} / \mathrm{g}$ (90\% of the initial value) during the initial 200 cycles. Then, it decreased slightly and became stable during the next 1800 cycles. The capacitance was about $370 \mathrm{~F} / \mathrm{g}$ for 2000 cycles. This indicated that after 2000 cycles of the charge-discharge operation, the electrodeposited Mn-Ni oxide maintained $86 \%$ of its initial specific capacitance and exhibited good cycling stability. 
Figure 7. Specific capacitance of the electrodeposited $\mathrm{Mn}-\mathrm{Ni}$ oxide electrode $0.5 \mathrm{M} \mathrm{Na}_{2} \mathrm{SO}_{4}$.

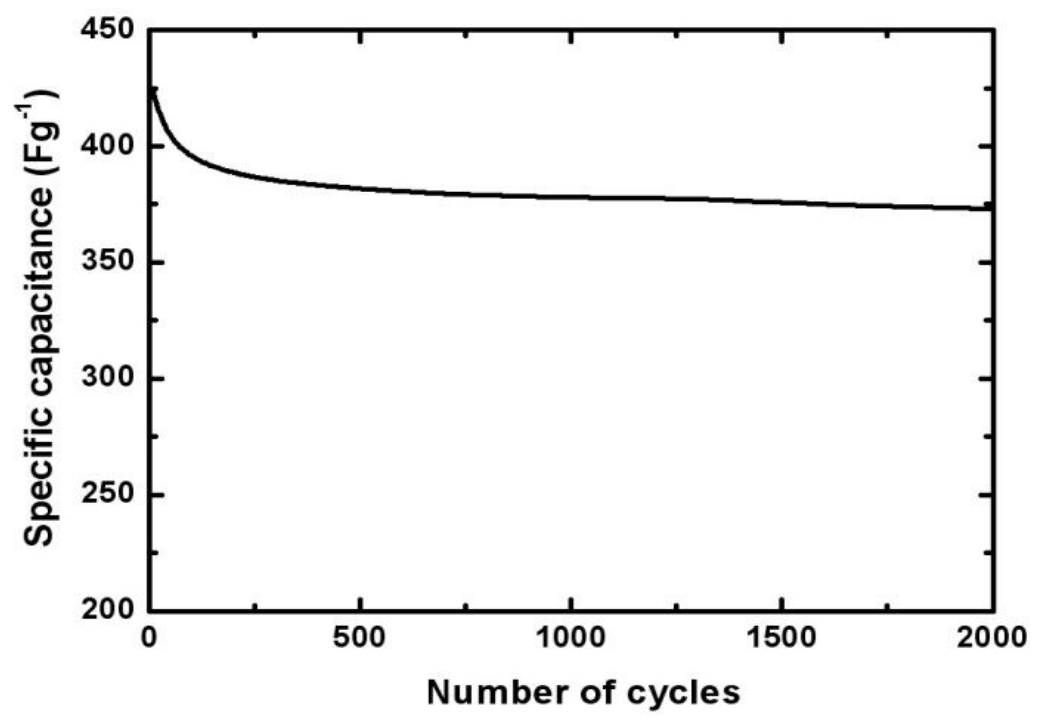

\section{Experimental Section}

Mn-Ni oxide films were electrodeposited on a graphite sheet. The graphite sheet was cut into a $10 \times 50 \mathrm{~mm}^{2}$ rectangular substrate and lacquered to expose an area of $10 \times 20 \mathrm{~mm}^{2}$ for electrodeposition. Prior to electrodeposition, the substrate was polished with a silicon carbide paper. The polished substrate was etched in a $20 \mathrm{wt} \%$ sulfuric acid solution at room temperature for $20 \mathrm{~s}$, and dipped into a solution of $2 \mathrm{M}$ methanol for $20 \mathrm{~s}$ to remove macro-level surface defects and contamination. Then, the substrate was cleaned in double distilled water and dried in an oven at $65{ }^{\circ} \mathrm{C}$ for $6 \mathrm{~h}$.

Manganese acetate $\left(\mathrm{Mn}\left(\mathrm{CH}_{3} \mathrm{COO}\right)_{2} 4 \mathrm{H}_{2} \mathrm{O}\right)$ and nickel chloride $\left(\mathrm{NiCl}_{2} 6 \mathrm{H}_{2} \mathrm{O}\right)$ were used as the sources of manganese and nickel, respectively. The concentrations of manganese acetate and nickel chloride were $0.1 \mathrm{M}$ and $0.2 \mathrm{M}$, respectively. The electrolytes were obtained by dissolving the above chemicals in deionized water. All chemicals were of analytical reagent grade supplied by Sigma-Aldrich (St. Louis, MO, USA).

The electrodeposition was carried out using a standard three-electrode cell. A saturated $\mathrm{Ag} / \mathrm{AgCl}$ electrode was used as a reference electrode and a graphite sheet having a size of $20 \times 70 \mathrm{~mm}^{2}$ (exposed area of $20 \times 35 \mathrm{~mm}^{2}$ ) prepared by the same aforementioned method was used as a counter electrode. During electrodeposition, a constant potential of $1.2 \mathrm{~V}$ versus the reference electrode of $\mathrm{Ag} / \mathrm{AgCl}$ from a stagnant electrolyte at room temperature $\left(24 \pm 1{ }^{\circ} \mathrm{C}\right)$ was applied using a computer-controlled potentiostat (Princeton Applied Research, VSP). The electrodeposition was done for $60 \mathrm{~s}$ in all cases. After deposition, the samples were washed with a deionized water jet, dried with flowing nitrogen gas, and annealed in an oven at $250 \pm 1{ }^{\circ} \mathrm{C}$ for $3 \mathrm{~h}$. Annealing of the samples was done to improve the adhesion of the Mn-Ni oxide films to the substrate.

The weight of the electrodeposited manganese-nickel oxides films were determined by a microbalance to an accuracy of $10 \mu \mathrm{g}$. The surface composition of the film was identified using $\mathrm{X}$-ray photoelectron spectroscopy (XPS). Microstructural analysis of the film was carried out using a high-power X-ray diffractometer (XRD, Rigaku, D/max- 2500V/PC), which used a $\mathrm{Cu} \mathrm{K}_{\alpha}$ radiation 
(wavelength $=0.154 \mathrm{~nm}$ ) as an incident beam and worked at $40 \mathrm{kV}$ and $150 \mathrm{~mA}$. Surface morphology of the film was examined using a field emission scanning electron microscopy (FE-SEM, Hitachi, S-4800, Tokyo, Japan). Nitrogen adsorption-desorption measurements were made using an adsorption analyzer (Micrometrics, ASAP 2010, Norcross, GA, USA) to obtain the pore size of the electrodeposited $\mathrm{Mn}-\mathrm{Ni}$ oxide film. The sample was outgassed for $6 \mathrm{~h}$ at $473 \mathrm{~K}$ prior to the measurements. The pore sizes were calculated based on the Barret-Joyner-Halenda (BJH) desorption method.

For electrochemical measurements, a platinum-coated titanium mesh $\left(2.5 \mathrm{~cm}^{2}\right.$ in size $)$ and a saturated $\mathrm{Ag} / \mathrm{AgCl}$ electrode were used as a counter electrode and a reference electrode, respectively. Cyclic voltammograms (CVs) were recorded between -0.2 and $1.0 \mathrm{~V}$ versus $\mathrm{Ag} / \mathrm{AgCl}$. The capacitance $(C)$ of an electrode can be calculated from the following Equation

$$
C=\frac{\mathrm{d} Q}{\mathrm{~d} V}=\frac{I}{\mathrm{~d} V / \mathrm{d} t}
$$

where $Q$ is the charge on the electrode, $V$ is its potential, $I$ is the average current, and $\mathrm{d} V / \mathrm{d} t$ is the voltage scanning rate. The specific capacitance of the electrodeposited manganese-nickel oxide electrode was obtained by dividing the capacitance by its respective weight. The weight of the electrodeposited manganese-nickel oxide films was measured using a microbalance with an accuracy of $10 \mu \mathrm{g}$. The constant current charge-discharge behavior of the manganese-nickel oxide electrode was investigated galvanostatically at a current of $5 \mathrm{~mA}$.

\section{Conclusions}

The electrodeposition of Mn-Ni oxide films for use as an electrochemical capacitor electrode was carried out in a bath containing manganese acetate and nickel chloride. SEM studies showed that the Mn-Ni oxide film was well covered with numerous nanofibers in a three-dimensional network. Porous spaces were also observed between the nanofibers, which are required for electrochemical capacitor applications. The XRD analysis revealed that the electrodeposited $\mathrm{Mn}-\mathrm{Ni}$ oxide film contained separate manganese oxide $\left(\gamma-\mathrm{MnO}_{2}\right)$ and nickel oxide $(\mathrm{NiO})$. The XPS spectra of the electrodeposited $\mathrm{Mn}-\mathrm{Ni}$ oxide film confirmed the presence of manganese (IV) oxide and nickel (II) oxide. From the XPS measurements, the surface composition of the film was determined to be $\mathrm{Mn}_{0.24} \mathrm{Ni}_{0.05} \mathrm{O}_{0.71}$. The cyclic voltammetry measurements showed that the electrodeposited Mn-Ni oxide electrode had a specific capacitance of $424 \mathrm{~F} / \mathrm{g}$ at a scan rate of $20 \mathrm{mV} / \mathrm{s}$. The stability test of the film exhibited good cycling stability in that the electrodeposited $\mathrm{Mn}-\mathrm{Ni}$ oxide electrode maintained $86 \%$ of its initial specific capacitance over 2000 cycles of the charge-discharge operation. Therefore, electrodeposition is a simple and promising method to fabricate Mn-Ni oxide films for electrochemical capacitor applications.

\section{Acknowledgments}

This work was supported by the National Research Foundation of Korea (NRF) grant funded by the Korea government (MEST) (2011-0029118 and 2012-004416), S-Oil Corporation, and an Ajou University Research Fellowship of 2010 (S-2010-G0001-00058). 


\section{Conflicts of Interest}

The authors declare no conflict of interest.

\section{References}

1. Simon, P.; Gogotsi, Y. Materials for electrochemical capacitors. Nat. Mater. 2000, 91, 845-854.

2. Burke, A. Ultracapacitors: Why, how, and where is the technology. J. Power Sour. 2000, 91, 37-50.

3. Zheng, J.P.; Cygan, P.J.; Jow, T.R. Hydrous ruthenium oxide as an electrode material for electrochemical capacitors. J. Electrochem. Soc. 1995, 142, 2699-2703.

4. Kandalkar, S.G.; Lee, H.-M.; Chae, H; Kim, C.-K. Structural, morphological, and electrical characteristics of the electrodeposited cobalt oxide electrode for supercapacitor applications. Mater. Res. Bull. 2011, 46, 48-51.

5. Pang, S.-C.; Anderson, M.A.; Chapman, T.W. Novel electrode materials for thin-film ultracapacitors: Comparison of electrochemical properties of sol-gel-derived and electrodeposited manganese dioxide. J. Electrochem. Soc. 2000, 147, 444-450.

6. Nam, K.-W.; Yoon, W.-S.; Kim, K.-B. X-ray absorption spectroscopy studies of nickel oxide thin film electrodes for supercapacitors. Electrochim. Acta 2002, 47, 3201-3209.

7. Rudge, A.; Davey, J.; Raistrick, I.; Gottesfeld, S.; Ferraris, J.P. Conducting polymers as active materials in electrochemical capacitors. J. Power Sour. 1994, 47, 89-107.

8. Hu, C.-C.; Tsou, T.-W. The optimization of specific capacitance of amorphous manganese oxide for electrochemical supercapacitors using experimental strategies. J. Power Sour. 2003, 115, 179-186.

9. Ghaemi, M.; Binder, L. Effects of direct and pulse current on electrodeposition of manganese dioxide. J. Power Sour. 2002, 111, 248-254.

10. Liu, J.-L.; Fan, L.-Z.; Qu, X. Low temperature hydrothermal synthesis of nano-sized manganese oxide for supercapacitors. Electrochim. Acta 2012, 66, 302-305.

11. Dubal, D.P.; Dhawale, D.S.; Salunkhe, R.R.; Fulari, V.J.; Lockhande, C.D. Chemical synthesis and characterization of $\mathrm{Mn}_{3} \mathrm{O}_{4}$ thin films for supercapacitor application. J. Alloy. Compd. 2010, 497, 166-170.

12. Lin, C.-K.; Chuang, K.-H.; Lin, C.-Y.; Tsay, C.-Y.; Chen, C.-Y. Manganese oxide films prepared by sol-gel process for supercapacitor application. Surf. Coat. Technol. 2007, 202, 1272-1276.

13. Jiang, R.; Huang, T.; Liu, J.; Zhuang, J.; Yu, A. A novel method to prepare nanostructured manganese dioxide and its electrochemical properties as a supercapacitor electrode. Electrochim. Acta 2009, 54, 3047-3052.

14. Wang, G.-X.; Zhang, B.-L.; Yu, Z.-L.; Qu, M.-Z. Manganese oxide/MWNTs composite electrode for supercapacitors. Solid State Ion. 2005, 176, 1169-1174.

15. Walanda, D.K.; Lawrance, G.A.; Donne, S.W. Hydrothermal $\mathrm{MnO}_{2}$ : Synthesis, structure, morphology and discharge performance. J. Power Sour. 2005, 139, 325-341.

16. Chuang, P.-Y.; Hu, C.-C. The electrochemical characteristics of binary manganese-cobalt oxides prepared by anodic deposition. Mater. Chem. Phys. 2005, 92, 138-145.

17. Chen, Y.-S.; Hu, C.-C. Capacitive characteristics of binary manganese-nickel oxides prepared by anodic deposition. Electrochem. Solid State Lett. 2003, 6, A210-A213. 
18. Wei, T.-Y.; Chen, C.-H.; Chien, H.-C.; Lu, S.-Y.; Hu, C.-C. A cost-effective supercapacitor material of ultrahigh specific capacitances: Spinel nickel cobaltite aerogels from an epoxide-driven sol-gel process. Adv. Mater. 2010, 22, 347-351.

19. Salunke, R.R.; Jang, K.; Lee, S.-W.; Ahn, H. Aligned nickel-cobalt hydroxide nanorod arrays for electrochemical pseudocapacitor applications. RSC Adv. 2012, 2, 3190-3193.

20. Sun, Z.; Firdoz, S.; Yap, E.Y.-X.; Li, L.; Lu, X. Hierarchically structured $\mathrm{MnO}_{2}$ nanowires supported on hollow Ni dendrites for high-performance supercapacitors. Nanoscale 2013, 5, 4379-4387.

21. Jayashree, R.S.; Kamath, P.V. Nickel hydroxide electrodeposition from nickel nitrate solutions: Mechanistic studies. J. Power Sour. 2001, 93, 273-278.

22. Berchmans, S.; Gomathi, H.; Rao, G.P. Electrooxidation of alcohols and sugars catalyzed on a nickel oxide modified glassy carbon electrode. J. Electroanal. Chem. 1995, 394, 267-270.

23. Strohmeier, B.; Hercules, D.M. Surface spectroscopic characterization of $\mathrm{Mn} / \mathrm{Al}_{2} \mathrm{O}_{3}$ catalysts. J. Phys. Chem. 1984, 88, 4922-4929.

24. Khawaja, E.E.; Salim, M.A.; Khan, M.A.; Al-Adel, F.F.; Khattak, G.D.; Hussain, Z. XPS, auger, electrical and optical studies of vanadium phosphate glasses doped with nickel oxide. J. Non-Cryst. Solids 1989, 110, 33-43.

(C) 2014 by the authors; licensee MDPI, Basel, Switzerland. This article is an open access article distributed under the terms and conditions of the Creative Commons Attribution license (http://creativecommons.org/licenses/by/3.0/). 